\title{
Tecnologias De Comunicação De Dados Letais
}

\author{
Débora de Castro Leal \\ Universidade de Siegen \\ Siegen, Alemanha \\ debora.dleal@uni-siegen.de
}

\author{
David Randall \\ Universidade de Siegen \\ Siegen, Alemanha \\ dave.randall@uni-siegen.de
}

\author{
Max Krueger \\ Universidade de Siegen \\ Siegen, Alemanha \\ maximilian.krueger@uni-siegen.de
}

\author{
Kaoru Misaki \\ International Institute of Socio- \\ Informatics \\ Bonn, Germany
}

\author{
Volker Wulf \\ Universidade de Siegen \\ Siegen, Alemanha \\ volker.wulf@uni-siegen.de
}

\begin{abstract}
RESUMO
Estudar as lutas políticas armadas pode colocar em evidência as complexas interações entre cultura, tecnologia, materialidade e conflito político. O presente artigo apresenta um relato da luta armada das FARC-EP, um dos guerrilheiros colombianos, com o exército colombiano. Documentamos como a comunicação se tornou uma infraestrutura de guerra crucial e ambígua, onde a súbita introdução de tecnologias de localização pelo exército colombiano representou uma ameaça letal para o grupo guerrilheiro. Nossos entrevistados relatam um processo de aprendizado severo para diminuir esse novo risco, contando com uma combinação de crenças e compreensão técnica significativa. Nesse estudo, introduzimos o conceito de contraapropriação como processo forçado de adaptação de práticas e apropriação de tecnologias durante um conflito.
\end{abstract}

\section{PALAVRAS-CHAVE}

Infraestrutura, Apropriação, Conflito Político, Guerra

\section{Introdução}

Os computadores e as tecnologias de informação e comunicação (TIC) tornaram-se uma componente crucial da infraestrutura de conflitos em todo o mundo. Neste artigo, relatamos as investigações realizadas na Colômbia com ex-combatentes do conhecido grupo guerrilheiro Forças Armadas Revolucionárias da Colômbia - Exército do Povo (FARC-EP). O grupo foi um dos principais protagonistas de um conflito que se prolongou por mais de 50 anos e envolveu vários grupos rebeldes de esquerda, paramilitares de direita, grupos criminosos, o exército nacional e

Permission to reproduce or distribute, in whole or in part, material extracted from this work, verbatim, adapted or remixed, as well as the creation or production from the content of such work, is granted without fee for non-commercial use, provided that the original work is properly credited. IHC 2019 - TRILHA ARTIGOS INTERNACIONAIS, Outubro 21-25, 2019, Vitória, Brasil. In Anais Estendidos do XVIII Simpósio Brasileiro sobre Fatores Humanos em Sistemas Computacionais. Porto Alegre: SBC. (C) 2019 by the author(s), in accordance with the terms of the Creative Commons Attribution-NonCommercial 4.0 International Public License (CC BY-NC 4.0) até mesmo os Estados Unidos através do acordo político denominado Plano Colômbia.

A guerra custou mais de 200 mil vidas [1] e gerou um dos maiores números de desabrigados internos do mundo [2]. Apesar do acordo de paz ter sido assinado em 2016, final de agosto de 2019, ex-combatentes retornaram à luta armada sobre o argumento de que o governo não cumpriu todos os acordos.

A seguir, mostraremos um resumo do doloroso processo de aprendizagem que os guerrilheiros tiveram de passar para se adaptarem a circunstâncias de atrito durante a guerra.

\section{Método de Pesquisa}

O local onde o estudo foi conduzido é uma comunidade de antigos guerrilheiros das FARC-EP, chamado Espaço Territorial de Treinamento e Reincorporação (ETCR). Cerca de 400 excombatentes vivem no espaço após o Acordo de Paz de Havana. Os métodos de pesquisa consistiram em uma análise exploratória de observações e entrevistas não estruturadas. Essas entrevistas permitiram que os entrevistados contassem histórias detalhadas [4]. A primeira autora esteve no ETCR por 28 dias, o terceiro e quinto autor estiveram por sete dias. Durante esse tempo, interagiram com os habitantes do acampamento e se envolveram em trabalho e atividades sociais. Os dados foram coletados na forma de notas de campo - total de 114 páginas - e interação com mais de 50 pessoas. Todas as interações foram realizadas em espanhol e, em algumas ocasiões, apoiadas por um tradutor, que mediou entre inglês e espanhol.

\section{Descobertas}

FARC-EP foi sempre uma organização predominantemente rural e sua presença nas cidades foi mínima. Isso limitava seu acesso às novas tecnologias e, como resultado, a tecnologia de que dispunham era simples. A infraestrutura tecnológica em que suas operações se apoiavam era principalmente papel e rádio e, em um estágio bastante tardio, a comunicação via rádio era auxiliada por meio de criptografia computadorizada. As tecnologias mais 
difundidas dos últimos 20 anos, telefones celulares e internet, foram pouco utilizadas e em nenhum momento desempenharam papel estratégico em suas operações. Dado que as suas operações dependiam da coordenação bem-sucedida de um grande número de combatentes divididos em pequenas unidades e distribuídos por uma vasta área, a comunicação era crucial. É notável que ela foi gerida com recursos extremamente limitados.

Em muitos aspectos, as FARC-EP evitaram a derrota por um inimigo tecnologicamente muito mais avançado que gozava do apoio do governo e dos militares dos EUA. A disponibilidade de infraestrutura tecnológica nesta guerra era radicalmente assimétrica: enquanto as FARC dependiam de tecnologias bastante simples, o governo colombiano tinha a sua disposição tecnologia de guerra altamente avançada. $\mathrm{O}$ uso de vários tipos de tecnologia de localização para realizar o bombardeio a acampamentos das FARC-EP, colocou a guerrilha sob alta pressão [5]. Uma vez que a presença das FARC-EP foi detectada, elas eram atacadas através de bombardeios direcionados. Com base nas características das infraestruturas descritas por Star e Bowker [8], a utilização destas tecnologias pelo exército colombiano pode ser descrita como uma "infra-estrutura de atrito". Esses dispositivos sociotécnicos consistem em um conjunto de ações e reações incorporadas em outros dispositivos materiais ou sociais. Por exemplo, o exército baseou-se no conhecimento de práticas específicas das FARC-EP, tal como encomendar suprimentos e bens de consumo nas regiões rurais. Dispositivos de localização foram feitos para serem invisíveis para as FARC-EP e foram a base para os ataques de bombardeio de precisão que o exército realizou.

As perdas forçaram os guerrilheiros a lidar com estes atritos. Eles aprenderam e desenvolveram gradualmente um conjunto de estratégias para evitar a localização do exército, com e muitas vezes sem o apoio da tecnologia. De fato, as estratégias consistiam muitas vezes em simples práticas de segurança: para evitar a localização através da detecção de calor, os combatentes começaram a empregar diferentes métodos de cozinhar alimentos e a dormir mais dispersos, de modo a emitir menos calor. Para escapar de câmeras ou sensores, eles usavam diferentes caminhos para chegar ao acampamento. Valas foram escavadas em diferentes locais para proporcionar oportunidades de abrigo, em caso de ataques.

Os dispositivos que nos foram descritos como "microchips" foram provavelmente os mais difíceis de serem identificados e combatidos. Sem um conhecimento profundo, é difícil adivinhar a função de um chip eletrônico a partir de sua aparência. Para evitar a detecção do acampamento através do chip, foi adotada uma estratégia simples: novos suprimentos eram colocados em áreas distantes do acampamento por um período de tempo, para ver se o local seria bombardeado. Mais tarde, eles começaram a escanear produtos e em outros foram usados choques elétricos para destruir quaisquer chips de rastreamento. As estratégias da FARC-EP e o desejo de adquirir conhecimento foram provavelmente cruciais.

Além da tentativa e erro, para entender as tecnologias, eles também abriam equipamentos e os reconstruíam num desejo de entender como a detecção funcionava e como encontrar formas de destruição de 'microchips'. O meticuloso processo de aprendizagem que os membros das FARC-EP tiveram que passar $\mathrm{e}$ as mudanças nas práticas para escapar da ameaça dos bombardeios é o que caracterizamos como contraapropriação. Como Stevens e Pipek [3] mencionam: "apropriação refere-se ao estabelecimento de novas práticas à luz das novas tecnologias" e "tais transformações podem ser um processo lento, despercebido, silencioso e evolucionário" [3]. Isto descreve adequadamente o doloroso processo de mudança pelo qual passou as FARC-EP para mitigar a perda de combatentes e amigos: foi um desenvolvimento gradual e lento de novas práticas à luz das novas tecnologias do oponente. $\mathrm{O}$ que o distingue do conceito estabelecido de apropriação é o fato de que as tecnologias das quais eles mudaram seu comportamento não eram próprias, mas aquelas usadas por outros. O termo "contraapropriação" não é inteiramente novo, ver [6] e [7]. No contexto de CSCW e IHC, usamos o termo para descrever um conflito assimétrico, onde um lado é forçado a mudar seu comportamento por conta da tecnologia usada pelo outro lado, enquanto o funcionamento da tecnologia permanece obscuro. A contraapropriação pode, mas não somente, envolver o uso da tecnologia e, além disso, precisa ser entendida como uma forma específica de resistência mais ampla ao sistema político, econômico e social.

\section{AGRADECIMENTOS}

Gostaríamos de agradecer aos nossos amigos e conhecidos colombianos. Mesmo aqueles que se encontram em situações vulneráveis têm-nos dado confiança e abertura. A sua vulnerabilidade é fortemente ilustrada pela morte violenta de um entrevistado e pelo desaparecimento do líder do ETCR visitado. O trabalho foi apoiado pela Universidade Nacional da Colômbia e pela bolsa de estudos para mulheres pesquisadoras em início de carreira da Universidade de Siegen.

\section{REFERÊNCIAS}

[1] Al Jazeera, 2013. Report says 220,000 died in Colombia conflict.. https://www.aljazeera.com/news/americas/2013/07/ 201372511122146399.html [2] Estadísticas del conflicto armado en Colombia, 2012. https://bit.ly/SXSPth

[3] G. Stevens and V. Pipek, 2018. Making Use: Understanding, Studying, and Supporting Appropriation. In Wulf, Pipek et al. (Eds.): Socio-Informatics: A Practice-Based Perspective on the Design and Use of IT Artifacts. $139-176$.

[4] J.A. Holstein and J.F. Gubrium, 2000. Constructing the life course. Rowman \& Littlefield.

[5] J. Schonau-Taylor, 2004. High Tech, Low Results: The Role of Technology in the US's Current Narcoterrorism War in the Andean Region and Why it is Failing. PhD Thesis. OregonStateUniversity.ISBN:978-1-4503-0000-0/18/06

[6] N.L. Peluso, 1992. Rich forests, poor people: Resource control and resistance in Java. Univ of California Press.

[7] P. Young, 2016. Ghanaian Woman and Dutch Wax Prints: The Counterappropriation of the Foreign and the Local Creating a New Visual Voice of Creative Expression. Journal of Asian and African studies 51, 3 (2016), 305-327.

[8] S.L. Star and G.C. Bowker, 2006. How to infrastructure. Handbook of new media: Social shaping and social consequences of ICTs (2006), 230-245. 